\title{
Uno como no hay otro. Patricio Núñez Henríquez
}

\author{
Victoria Castro $^{1,2}$
}

Un personaje noble y casi de otro mundo fue Patricio, gran amigo. Compañero nuestro de trabajo en sus últimos diez años de vida. Tan humano, tan caballero, sutil y gentil. Quién lo diría, con su apariencia de hombre grande... Nos acompañó en dos proyectos de investigación CONICYT desarrollados en la costa arreica junto a Carlos Aldunate y Varinia Varela. En estas convivencias compartimos con muchos estudiantes, varios de ellos tesistas y cada uno tuvo una experiencia particular con él. Nos dividíamos en dos grupos y él fue parte del equipo sur, al sur de Cobija y otros de nosotros al norte de este lugar. Habíamos definido ese espacio de unos 35 kilómetros lineales, como nuestra área de estudio. En las mañanas y en las tardes nos reuníamos todos en el cordial desayuno y en la noche, en las sabrosas comidas. Sabrosas en toda la extensión de la palabra.

Sabía mucho. Un gran observador y hombre cercano al mar y a la vida, a la sutileza de la cotidianidad. De una sencillez notable. De un hipismo y porfía también notable. En lo primero, su sencillez, creo que fue un rasgo que lo marcó toda su vida en sus múltiples aspectos. Como arqueólogo, destaca su acertado escrito junto con Vjera Zlatar sobre la coexistencia de comunidades costeras prehispánicas en el norte de Chile (Núñez y Zlatar 1977, 1980). Un verdadero modelo para entender diferentes formas de complejidad de una sociedad temprana, sin aparatajes pretenciosos. Con su perspicacia vieron, con profundidad y sencilla modernidad, al espacio y al tiempo más que una sucesión ordenada, como un escenario abierto para compartir experiencias entre distintos grupos sociales. Aun con el valor que tiene, esta propuesta ha sido poco considerada por nuestra academia tanto más interesada en la producción anglosajona. De estos escritos saltó a su llamada de atención sobre tierras altas y el complejo agrícola de Socaire (Núñez 1983), donde aún queda prácticamente todo por hacer.

Tan temprana comprensión del pasado en Patricio, se debe a un profundo conocimiento de la historia, su disciplina de origen, así como a su visión del arte y sus posibilidades especialmente en las comunidades preeuropeas, como tan eruditamente lo deja plasmado en su libro Vivir después de Soñar (Núñez 2016) que generosamente hizo parte del proyecto FONDECYT que compartimos, lo que consta en los agradecimientos de esta obra.

Con la misma seriedad, Patricio quiso hacer difusión científica. Escribió varios textos de divulgación, en donde navega los mares desde la historia (Núñez 2015), su disciplina matriz, a los que suma diferentes discursos (Núñez 2009), dedicados a los niños, el público no especializado (Núñez 2005), e incluso para un mundo culto en escritos que dejó como legado póstumo, como por ejemplo "Corsarios patriotas del cono sur de América", recientemente publicado, después de su muerte, en Le Monde Diplomatique (Núñez 2018). Cada vez que pudo, donó un ejemplar de sus escritos a los estudiantes. Algunos lo recuerdan como risueño, amigable, sencillo y, especialmente, destacan su amor al mar y su compañerismo.

Recordar a Patricio es de algún modo sentir las ganas de estar sentada en una nube y observarlo, como si él fuera el principito de Saint Exupery, tan valiente, con su espada defendiendo nobles valores, tan honesto y tan consecuente que faltan palabras o una poesía para regalarle a esta persona sencilla y amada, interesado en muchos temas. Por ejemplo, tempranamente estudió los problemas de género, por lo que es recordado con mucho cariño entre las colegas de Jujuy, a donde viajaba para compartir en sus seminarios sobre el tema.

No se crea eso sí que fuera una persona perfecta, si nadie lo es. No, porque era porfiado y llevado de sus ideas como ninguno, desordenado, incapaz de recibir órdenes burocráticas. Que feliz fue con su jubilación temprana. Gozó de la vida y escribió como quiso. Solo tuvo que soportar que yo lo persiguiera para conseguir una boleta para pagar sus honorarios; no importa cuánto te hiciera rabiar; siempre tuvo un noble amigo como Rodolfo que le solucionó esas mañas de niño; por lo tanto del tema de las rendiciones de fondos; mejor ni hablar. "Para que me pagas si yo no necesito; si soy feliz estando en

\footnotetext{
${ }^{1}$ Departamento de Antropología, Universidad de Chile, Santiago, Chile. vcastror53@gmail.com

${ }^{2}$ Departamento de Antropología, Universidad Alberto Hurtado, Santiago, Chile.
} 
terreno con ustedes y compartiendo" me decía. Libre como un ave, vivió sus últimos años como el picaflor que fue en su juventud, feliz junto a su compañera Adriana.

\section{Referencias Citadas}

Núñez, P. 1993. Un canal de regadío incaico. Socaire-Salar de Atacama. Actas del XII Congreso Nacional de Arqueología Chilena. Boletín del Museo Regional de la Araucanía 4:259-268.

Núñez, P. 2005. Vivir y Morir en los Andes. Reflexiones. Andros Impresores, Santiago.

Núñez, P. 2009. Tawantinsuyu y España: Dos Tradiciones y el Siglo XVI con Tópicos de Ciencia y Tecnología. Universidad de Antofagasta, Antofagasta.

Núñez, P. 2015. El Arte de Navegar y de la Construcción Naval. Museo Augusto Capdeville Rojas, Taltal.

Núñez, P. 2016. Vivir después de Soñar. Museo Augusto Capdeville Rojas, Taltal.
Núñez, P. 2018. Corsarios patriotas del cono sur de América. Le Monde Diplomatique, http://sc.mondediplo.com/article. php3?id_article $=5685$.

Núñez, P. y V. Zlatar 1977. Tiliviche-1b y Aragon I (Estrato V): Dos comunidades pre-cerámicas coexistentes en Pampa del Tamarugal, Pisagua-Norte de Chile. Actas y Trabajos Ill Congreso Peruano "EI Hombre y la Cultura Andina" Tomo 2, pp. 734-736.

Núñez, P. y V. Zlatar 1980. Coexistencia de Comunidades Recolectoras-Cazadoras. Actas del V Congreso Nacional de Arqueología Argentina. Tomo 1, pp. 79-92, Universidad Nacional de San Juan, San Juan.

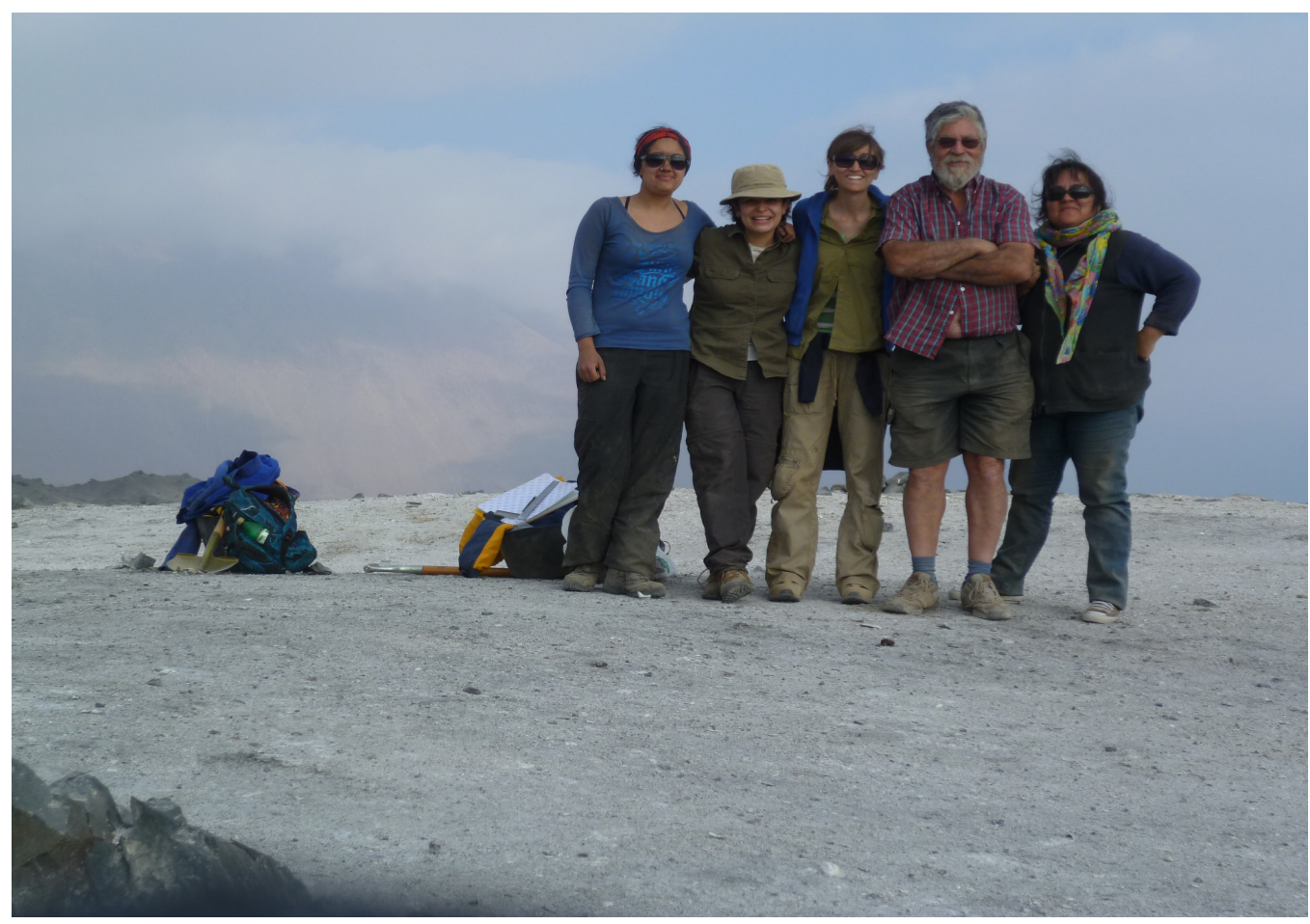

Equipo Sur, Fondecyt 1100951. De izquierda a derecha: Valentina Varas, Jimena Ruz, Javiera Letelier, Patricio Núñez, Varinia Varela, 2011 (imagen cortesía de Victoria Castro). 


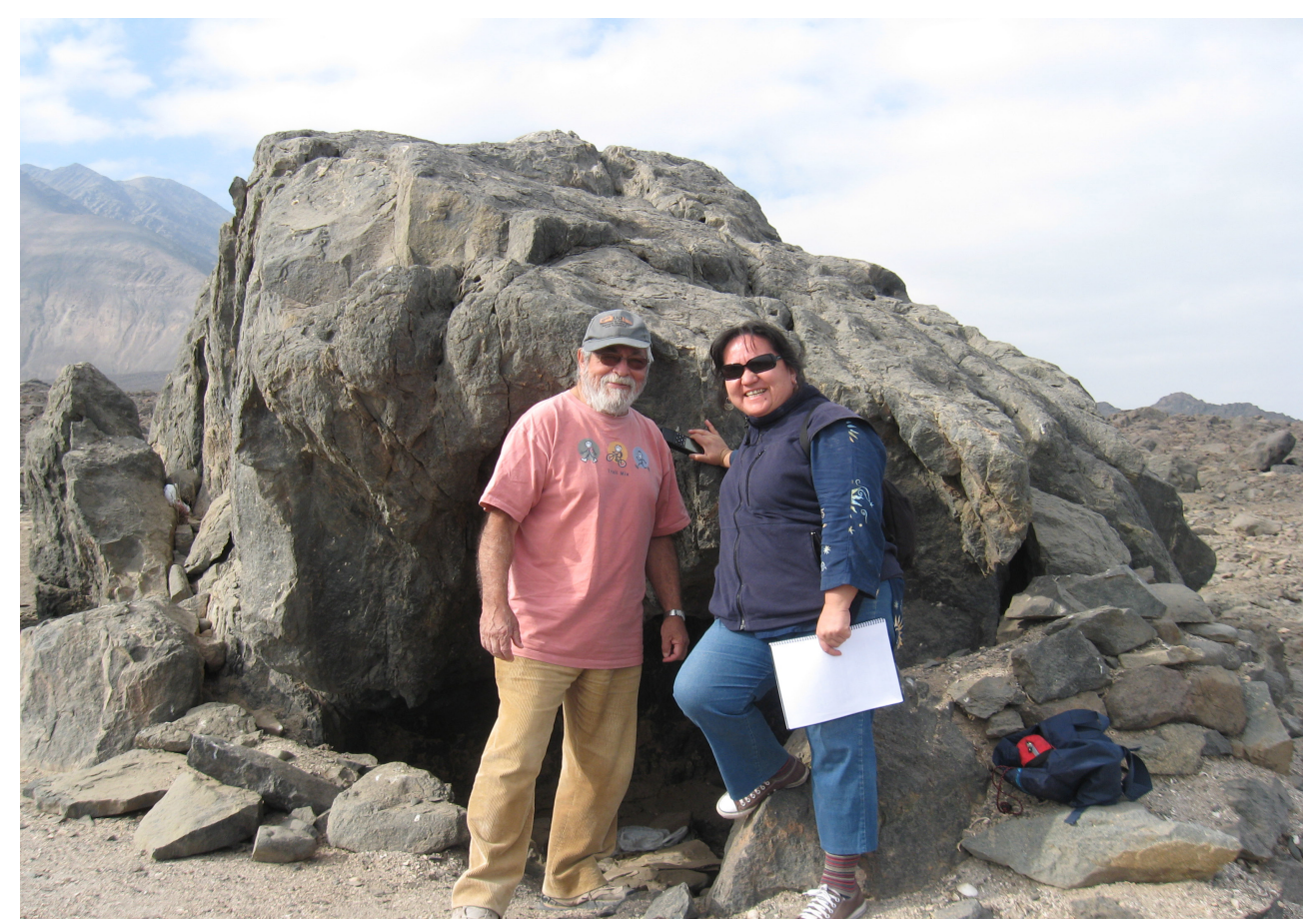

Alero Caleta El Fierro, costa arreica, región de Antofagasta, Fondecyt 1100951. Patricio Núñez y Varinia Varela, 2011 (imagen cortesía de Victoria Castro).

\section{Bibliografía}

\section{Principales Contribuciones de Patricio Núñez Henríquez}

Goñi, A. y P. Núñez 1971. Cueva 85, Distrito Tahai, Isla de Pascua. Actas del VI Congreso Nacional de Arqueología Chilena, pp. 371-396. Boletín de Prehistoria de Chile, Número Especial, Santiago.

Núñez, L., V. Zlatar y P. Núñez 1972-73. Reciente prospección de sitios arqueológicos componentes de un circuito transhumántico entre la costa y el borde occidental de la Pampa del Tamarugal, norte de Chile. Etnia 16/17:1-16.

Núñez, P. 1974. Nota sobre la aldea preagrícola de Caleta Huelén 42, desembocadura del río Loa. Norte de Chile. Serie Documentos de Trabajo 5:27-43.

Núñez, P. y V. Zlatar 1974. “Tarapacá Viejo”. Serie Documentos de Trabajo 5:2-4.

Núñez, L., V. Zlatar y P. Núñez 1975. Caleta Huelén 42: una aldea temprana en el norte de Chile (nota preliminar). Revista Hombre y Cultura 2 (5):67-103.

Núñez, P. 1976. En torno a la arqueología y la restauración monumental. Serie Documentos de Trabajo 7:9-14.

Núñez, P. y V. Zlatar 1976. Radiometría de Aragón-1 y sus implicancias en el precerámico costero del norte de Chile. Actas y Memorias del IX Congreso Nacional de Arqueología Argentina, I parte, pp. 105-118, Mendoza.
Núñez, P. y V. Zlatar 1977. Tiliviche-1 b y Aragon I (Estrato V): Dos comunidades pre-cerámicas coexistentes en Pampa del Tamarugal, Pisagua-Norte de Chile. Actas y Trabajos Ill Congreso Peruano "EI Hombre y la Cultura Andina" Tomo 2, pp. 734-736.

Núñez, P. y V. Zlatar 1980. Coexistencia de Comunidades Recolectoras-Cazadoras. Actas del V Congreso Nacional de Arqueología Argentina. Tomo 1, pp. 79-92, Universidad Nacional de San Juan, San Juan.

Núñez, P. 1983. Aldeas tarapaqueñas. Notas y comentarios. Chungara Revista de Antropología Chilena 10:29-37.

Núñez, P. 1984. La antigua aldea de San Lorenzo de Tarapacá. Norte de Chile. Chungara Revista de Antropología Chilena 13:53-65.

Núñez, P. 1986. Arqueología y restauración monumental: Dos ciencias sociales. Chungara Revista de Antropología Chilena 1617:275-278.

Núñez, P. 1993. Posibilidades agrícolas y población del Incario en el área atacameña. Norte de Chile. Actas de XII Congreso Nacional de Arqueología Chilena. Boletín del Museo Regional de la Araucanía 4:259-267.

Núñez, P. 1993. Un canal de regadío incaico. Socaire-Salar de Atacama. Actas del XII Congreso Nacional de Arqueología Chilena. Boletín del Museo Regional de la Araucanía 4:259-268. 
Núñez, P. 1995. Guía de la Exposición "Diseños en la Textilería del Norte de Chile”. $1^{\text {a }}$ edición. Universidad de Antofagasta, Antofagasta.

Núñez, P. 1997. Mujer, Hombre y Desierto Costero. Habitantes Indígenas Prehispanos del Litoral del Norte de Chile. Universidad de Antofagasta, Antofagasta.

Núñez, P. 1999. Doce Milenios. Una visión Social de Género de la Historia del Norte Grande de Chile. Universidad de Antofagasta, Antofagasta.

Núñez, P. 2000. El Poder en las Comunidades Prehispanas del Norte de Chile. Universidad de Antofagasta, Antofagasta.

Núñez, P. 2000. Estudio del arte y la artesanía prehispánicas en el norte de Chile. Actas III Congreso Chileno de Antropología. Tomo I, pp.350-361.

Núñez, P. 2001. Chacance: Los Primeros Pampinos. Museo Comuna de María Elena, Tocopilla.

Núñez, P. 2001. Nuestras Identidades: Reflexiones. A propósito de la Prehistoria de Tarapacá y Antofagasta. Instituto de Investigaciones Antropológicas, Universidad de Antofagasta, Antofagasta.

Muñoz, E., P. Núñez y M. Bahamondes 2001. Conservación y Restauración del Sitio Arqueológico $N^{\circ} 19$ de San Pedro de Atacama. Ministerio de Educación, Consejo de Monumentos Nacionales, Santiago.
Núñez, P. 2003. Vivir el Mar. Instituto de Investigaciones Antropológicas, Universidad de Antofagasta, Antofagasta.

Núñez, P. y R. Contreras 2003. Pinturas Prehispánicas de Taltal. Impresión Ercilla S.R.L., Antofagasta.

Núñez, P. 2005. Vivir y Morir en los Andes. Reflexiones. Instituto de Investigaciones Antropológicas, Universidad de Antofagasta, Antofagasta.

Núñez, P. y R. Contreras 2006. El arte rupestre de Taltal, norte de Chile. Actas del V Congreso Chileno de Antropología, pp. 348357. Colegio de Antropólogos de Chile, San Felipe.

Núñez, P. y R. Contreras 2008. El arte rupestre de Taltal, Norte de Chile. Taltalia 1:77-85.

Núñez, P. 2009. Tawantinsuyu y España: Dos Tradiciones y el Siglo XVI con Tópicos de Ciencia y Tecnología. Instituto de Investigaciones Antropológicas, Universidad de Antofagasta, Antofagasta.

Núñez, P. y R. Contreras 2011. Arte abstracto y religiosidad en el arcaico costero: Punta Negra-1c, Paposo, Taltal, norte de Chile. Taltalia 4:33-62.

Núñez, P. 2015. El Arte de Navegar y de la Construcción Naval. Museo Augusto Capdeville Rojas, Taltal.

Núñez, P. 2016. Vivir después de Soñar. Museo Augusto Capdeville Rojas, Taltal. 